\title{
Trabalhonecessário
}

ISSN: 1808 - 799X

ANO 12, № 19 - 2014

\section{REPARTIÇÃO SUSTENTADA NA ÉTICA DA NECESSIDADE: UMA POSSIBILIDADE NO TRABALHO COOPERADO E AUTOGESTOR}

Vilma Margarete Simão ${ }^{1}$

\section{RESUMO}

Este ensaio aborda questões do espaço de materialização da ética, os valores que predominam na sociedade contemporânea e a relação entre ética e trabalho. Neste sentido, o texto trata da ética e da participação no resultado trabalho na sociedade moderna e da superação da ética burguesa como pressuposto para a conquista da ética emancipatória. Para versar o tema, o ensaio acerca-se dos seguintes subtemas: trabalho livre e criativo como condição humana; limites e possibilidades da prática cooperativada na construção de uma nova racionalidade ética; limites da superação da produção da riqueza pelo sistema cooperativo no interior do sistema capitalista.

Palavras-chave: Trabalho. Repartição. Ética.

\section{ABSTRACT}

This essay addresses issues of space of materialization of the ethics, the values that prevail in contemporary society and the relationship between ethics and work. In this sense, the text deals with ethics and participation in the work result in modern society and the overcoming of bourgeois ethics as a prerequisite for the achievement of the emancipatory ethic. To address the topic, the essay near the following themes: work free and creative as the human condition; limits and possibilities of practical cooperative management in building a new rationality ethics; overcoming the limits of production of wealth by the cooperative system within the capitalist system.

Keywords: work, reboot, ethics.

1 Prof.a Dr.a do Departamento de Serviço Social da Fundação Universidade Regional de Blumenau. (vilmasimao@furb.br) 


\section{Trabalhonecessário}

ISSN: 1808 - 799X

ANO 12, № 19 - 2014

\section{INTRODUÇÃO}

No pensamento marxiano aqui abordado, o principal valor da ética emancipatória é o trabalho livre e criativo, ou seja, como essência humana.

Deste modo, pela ação humana, vai sendo desmaterializada a ética contemporânea sustentada na racionalidade econômica do valor de troca e edificado o espaço da materialização da ética emancipatória, na qual as relações de sociabilidade são mediadas pelo valor de uso e o trabalho é realizado como condição humana e não como condição do capital. Assim, ter-se-ia a possibilidade de todos satisfazerem outra necessidade humana básica: a da autonomia como possibilidade de criação e decisão - numa sociedade em que o trabalho estaria ao alcance de todas as pessoas e o estímulo para desenvolvê-lo seria o valor de uso.

Sem o trabalho, é inviável qualquer produção de bens e, através dele, conquista-se a autonomia com a produção dos instrumentos necessários à transformação da natureza. Para Marx, o trabalho é a essência humana, no entanto, somente aquele viabilizador de criação e, consequentemente, de objetivação, pois através de sua criação a pessoa o verá como fonte de realização humana. E o trabalho livre será possível com a livre associação de produtores, com a presença da cooperação voluntária e da autonomia na organização e gestão do trabalho.

Para tratar do tema, o ensaio aborda os seguintes itens: valores predominantes na sociedade contemporânea e a construção da ética emancipatória; trabalho livre e criativo como condição humana; limites e possibilidades da prática cooperativada na construção de uma nova racionalidade ética que emancipa o humano-societário; e limites da superação da produção da 


\section{Trabalhonecessário}

ISSN: 1808 - 799X

ANO 12, № 19 - 2014

riqueza pelo sistema cooperativo no interior do sistema capitalista na concepção de István Mészáros.

\section{QUAL O ESPAÇO DE MATERIALIZAÇÃO DA ÉTICA?}

A ética só se materializa na relação com o outro. O que a pessoa faz para si mesma, no silêncio de sua privacidade, sem causar prejuízo a outrem não é preocupação ética. Pois, o campo da ética é a ação humana desenvolvida nas práxis sociais, sendo ela orientada por valores historicamente construídos e socialmente aceitos como orientadores de um agir virtuoso. Então, a materialidade dos valores éticos é a própria prática humana, a qual é historicamente determinada. Bem por isso é possível se falar de uma ética conservadora do status quo e de uma ética renovadora, transformadora dos valores que orientam o agir humano. Uma nova orientação poderá ter como valor central a igualdade social e a distribuição solidária da riqueza produzida pelos seres humanos, portanto, da autonomia coletiva e não limitada à autonomia individual, descolada das relações sociais. Neste modo de conceber a ética perpassa a ideia de uma vida social justa, com a superação das injustiças econômicas. Assim, a ética se volta sobre as relações sociais; em primeiro lugar, esquece o céu e se preocupa com a terra, procurando apressar a construção de um mundo mais humano, onde se acentua o aspecto de uma justiça econômica, embora esta não seja a única característica desse mundo almejado.

Quando compreendida criticamente a dimensão ética da realidade social, sabendo-se que os atos morais e os valores são históricos, e assim compreendendo-os, é coerente olhá-los numa perspectiva de totalidade e de movimento, indagando sobre as possibilidades objetivas de realização dos 


\section{Trabalhonecessário}

ISSN: 1808 - 799X

ANO 12, № 19 - 2014

valores essenciais ao homem, entendido como ser social consciente, livre e histórico.

A ética é campo apropriado para a reflexão do agir humano, em que princípios orientam tal reflexão. Nessa perspectiva, buscam-se elementos reflexivos que contribuam para as escolhas éticas na vida social e sobre as possibilidades de um redimensionamento do agir na vida privada ou profissional, tendo em vista as suas implicações éticas na direção de um projeto social responsável e compromissado com um dos princípios éticos fundamentais, como liberdade, justiça, igualdade, democracia e solidariedade.

A ética é historicamente determinada, o que significa que as mudanças e transformações societárias alteram a base das relações sociais e, com elas, os valores também se alteram. Assim, também se alteram a moral e a ética social.

\section{VALORES PREDOMINANTES NA SOCIEDADE CONTEMPORÂNEA E A CONSTRUÇÃO DA ÉTICA EMANCIPATÓRIA}

$\mathrm{Na}$ sociedade capitalista, a base dos valores é a presença de relações sociais marcadas pela presença da apropriação individual da riqueza socialmente produzida e, portanto, da racionalidade econômica instrumental que transforma tudo em valor de troca e mantém o capital como finalidade da produção de riqueza, e não importando a riqueza de produção.

Então, coadunado com o objetivo da apropriação da riqueza ou da produção de riqueza, vê-se exacerbar, entre outros, valores individualistas que valoram a tecnificação das formas sociais de vida e trabalho, com uma racionalidade técnica que se confunde com a racionalidade da própria alienação, fragmentação do ser humano (só importando a competência no seu ofício), 


\section{Trabalhonecessário}

ISSN: 1808 - 799X

ANO 12, № 19 - 2014

predomínio da mercadoria sobre o ser humano, máxima eficiência com o máximo de conveniência individual e bens materiais como força humana.

Assim, nesta sociedade moderna, a ação humana tem como sujeito um "um ser genérico" alienado, orientado para a posse e para o mercado, ao mesmo tempo que submete o trabalhador/produtor à escravidão de suas necessidades. Superar esta ética burguesa - que concebe a exploração, a desigualdade social, a cooperação forçada e a ausência de autonomia dos produtores como condição natural e, portanto, aceitável - é conquistar uma ética emancipatória.

Para Marx, a emancipação humana é ação na busca da supressão das relações de exploração. Na Introdução à Crítica da Filosofia do Direito de Hegel, artigo publicado nos Anais Franco-Alemães, o proletariado (verdadeiro produtor de coisas úteis) aparece como o autor de sua emancipação e, pelo mesmo processo, de toda a humanidade. Apoiado nessa descoberta, Marx examinou a Questão judaica com o objetivo de explicar a relação entre emancipação política e emancipação humana, colocando no dinheiro e na propriedade privada a fonte da alienação humana.

Já em $A$ Miséria da Filosofia Marx se posicionara a respeito da emancipação, afirmando que são as mesmas pessoas que estabelecem as relações sociais, de acordo com a sua produtividade material, que produzem também os princípios, as ideias, os valores, de acordo com suas relações sociais. E como são produzidas pelas pessoas em relação umas com as outras, são tão pouco eternas quanto as relações que traduzem. Mas qual a relação entre ética e trabalho? Qual a ética do trabalho? Qual a relação entre ética e sentido do trabalho?

Se a ética se materializa na relação com o outro e ela se orienta pelos valores socialmente aceitos como apropriados para o agir humano, a forma como produzimos e reproduzimos a vida revela nossos próprios valores. Então, concebendo que produção é fonte de uma rica produção e que só é possível pela 


\section{Trabalhonecessário}

ISSN: 1808 - 799X

ANO 12, № 19 - 2014

atividade humana, o trabalho passa a ter valor ético no sentido de que a não realização dele é deixar de contribuir na produção de uma riqueza que será por todos e todas desfrutada. Deste modo, produção e trabalho estão dialeticamente relacionados e são tanto uma atividade do ser singular quanto do ser genérico. Então, de acordo com Marx (Grundrisse), produção pode ser entendida tanto como atividade do indivíduo singular como também num sentido mais amplo, de metabolismo social que englobaria em si o trabalho, bem como as demais relações travadas pelos indivíduos produtores no interior de seu processo de produção e reprodução de suas vidas (apud VIEIRA, 2004).

Pode-se dizer, segundo Karl Marx, que o trabalho não funda o ser singular (individual), mas é, sem dúvida, fundante do ser genérico (ser social). Segundo escreve Sérgio Lessa (1999), diante de uma necessidade, o indivíduo projeta, em sua consciência, o resultado de cada uma das alternativas, as avalia e escolhe aquela que julga mais conveniente para atender à necessidade. Escolhida a alternativa, o indivíduo age objetivamente, isto é, transforma a natureza e constrói algo novo. Este movimento de transformar a natureza a partir de uma prévia ideação é denominado, por Marx, "trabalho" e é ele, o trabalho, "a essência subjectiva da propriedade privada, a propriedade privada enquanto atividade para si própria, como sujeito, como pessoa" (MARX, 1989, p. 184). Portanto, é o trabalho que possibilita o desenvolvimento histórico, pois, através dele, vamos produzindo os objetos de satisfação de nossas necessidades. Sendo assim, podemos concluir ser o trabalho uma necessidade, antes de tudo, social.

A produção humana, que se realiza pelo trabalho, é, para Marx, um complexo que tem por determinação fundamental seu caráter social. Então, uma produção, que é possível pela interação de produtores associados, é campo característico da sociabilidade e será sustentada pelos valores éticos próprios de cada civilidade, objetivados pelo ato humano de produzir. Portanto, tal sociabilidade é inseparável do ato humano de produzir, do trabalho, não só pela 


\section{Trabalhonecessário}

ISSN: 1808 - 799X

ANO 12, № 19 - 2014

natureza em si deste ato, mas pela própria constituição do indivíduo que o leva a cabo. Karl Marx demonstra, pela positividade da produção caracteristicamente humana, que o ser humano é um ser social. Este ser social, saturado de um viver em comum das pessoas, constitui-se como a substância concreta dos indivíduos, a qual delimita toda a série de expressões e atividades deles.

A partir de Marx, "os indivíduos, então, realizariam e renovariam, através de cada um de seus atos produtivos, toda a malha societária que os define e os faz humanos" (apud VIEIRA, 2004, p. 32). Mas qual o caráter fundante da determinação da sociabilidade? É a atividade sensível, ou seja, o ser humano como ser ativo. Para Marx, o ser humano é ser social precisamente porque se autoconstitui, produzindo sua vida própria ao produzir outros seres, e, ainda, porque o faz sempre por meio e no interior de uma dada sociabilidade.

Nos Manuscritos econômico e filosófico, de 1844, Marx escreve que o interesse como razão da ação individual não é mais que a expressão da redução das necessidades de avidez, e, para reencontrar as necessidades verdadeiramente humanas, só com a superação da alienação e com o desaparecimento do interesse como motivação do agir em sociedade. Então, na produção social de riqueza eticamente orientada pelas necessidades humanas, reinarão princípios de utilidade social, contrapostos à vergonha social da apropriação individual e privada da riqueza socialmente produzida. Daí, finalmente, necessidade e prazer perderão sua falsa natureza egoísta, na qual a natureza de pura utilidade foi perdida. De acordo com Potyara A. P Pereira, nesta passagem, Marx deixa entender que necessidade é um conceito extraeconômico, no qual o bem-estar dos homens estaria acima dos interesses do capital.

Tanto é assim que concebia como uma expressão da alienação capitalista a redução do conceito de necessidades à necessidade econômica para a qual o fim da produção não é a satisfação das necessidades, mas a valorização do capital. (PEREIRA, 2002, p. $60)$. 


\section{Trabalhonecessário}

ISSN: 1808 - 799X

ANO 12, № 19 - 2014

A extensão das necessidades humanas, para além das básicas, para a manutenção da capacidade de trabalho e o modo de satisfazê-las são historicamente construídas. Por isso dependem de diferentes fatores, mas, principalmente o grau de civilização e das condições em que se formou a classe dos trabalhadores livres com seus hábitos e exigências peculiares (MARX, 2005, p. 201a). Se as necessidades humanas e o modo de satisfazê-las são historicamente determinados, o trabalho individual de cada ser humano não é suficiente para mantê-lo em plena capacidade de trabalho. Por outro lado, se "o trabalho de cada ser humano fosse apenas suficiente para produzir seus próprios alimentos, não haveria nenhuma propriedade [...]" (MARX, 2005, p. 580b). Então, dependerão do tipo de relações sociais estabelecidas para se formar o tipo de necessidades e o como atendê-las. Com a propriedade coletivizada, ainda assim o trabalho individual, por questões de sociabilidade sustentada na cooperação e na solidariedade, deixará um excedente, ou seja, a cota-trabalho maior do que aquela necessária à própria sobrevivência.

Seguindo a reflexão de Pereira (2002, p. 59) e nas próprias palavras de Marx (1983, p. 202-203), “[...] o homem é, no sentido mais literal, um zôon politikhón, não só um animal sociável, mas um animal que só em sociedade [...] poderá produzir". Ou o ser humano produz

[...] os objetos de sua necessidade e, ao mesmo tempo, cria também os meios para satisfazê-la. Já, no caso dos animais, as suas necessidades e seus objetos de satisfação já vêm 'dados' pela sua constituição biológica (HELLER, 1998, p. 44 apud PEREIRA, 2002, p. 59).

Pela condição de ser enquanto político e social, o ser humano tem necessidades muito além das ditas naturais ou biológicas e, ao mesmo tempo, cria as condições de satisfazê-las.

Podemos dizer que o trabalho permite a todos os humanos o atendimento de necessidades social e historicamente determinadas, dada a capacidade social 


\section{Trabalhonecessário}

ISSN: 1808 - 799X

ANO 12, № 19 - 2014

de produção de riquezas. Mas para produzir riqueza é imprescindível a obtenção das condições objetivas para o desenvolvimento do trabalho: possuir os instrumentos de trabalho, os meios de produção e a força de trabalho ou capacidade de trabalho. E apesar de essas condições objetivas serem resultado de toda a coletividade de trabalhadores/produtores, no imediato a riqueza aparece falsamente como realização do ser humano singular. Contudo, o modo de produção moderno evidencia o ser genérico, ou seja, a produção como resultado social. Este modo de produção possui como um de seus traços fundamentais aquele pelo qual necessariamente o indivíduo não produz visando unicamente à satisfação de suas necessidades pessoais, mas também visando satisfazer necessidades sociais.

O surgimento do indivíduo, tal como o conhecemos na modernidade, resulta da distinção do homem em relação às demais condições objetivas do trabalho. Com a presença da ética emancipatória no seio das relações sociais, o indivíduo deixa de ser mero elemento do processo de produção, para tornar-se trabalhador livre, fim em si do trabalho. Em formas anteriores da produção, o indivíduo ativo não só dependia para sua produção de uma comunidade natural, como só existia como indivíduo ativo exclusivamente no interior daquela comunidade - em relação à qual ele não tinha a menor chance de escolha. $\mathrm{Na}$ forma moderna da produção, esse indivíduo encontra-se desprendido em relação a todos os laços de propriedade natural anteriores. Encontra-se livre em relação a todas as condições inorgânicas de existência consideradas como condição natural de produção - por exemplo, a terra - e, ao mesmo tempo, em relação à forma de comunidade pressuposta por todas essas relações de propriedade anteriores (VIEIRA, 2004, p. 30).

Para Marx o trabalho é atividade que transforma a natureza, promovendo a humanização da natureza pelos indivíduos. Nas palavras do próprio autor: 


\section{Trabalhonecessário}

ISSN: 1808 - 799X

ANO 12, № 19 - 2014

[...] a natureza não constrói nem máquinas, nem locomotivas, nem caminhos de ferro, nem telégrafos elétricos, nem máquinas de fiar automáticas, etc. Trata-se de produtos da indústria humana: material natural transformado em órgãos da vontade humana sobre a natureza ou de seu exercício na natureza. (1985, p. 57).

"Se, por um lado, trabalho é subjetivação de objetividades, qual seja, de 'submissão dos objetos a um fim subjetivo', por outro, ele é, também, objetivação de potencialidades humanas, expressão de vida" (VIEIRA, 2004, p. 44). Porém, segundo Karl Marx, o trabalho forçado, imposto pelo exterior, em que o produtor não tem autonomia na própria realização do trabalho, o não trabalho representará a liberdade e a felicidade. Considerar o trabalho unicamente como sacrifício e como instância que põe valores, como preço que é pago pelos objetos e lhes dá, por sua vez, preço, segundo eles custem mais ou menos trabalho, é uma determinação puramente negativa.

\footnotetext{
Uma coisa puramente negativa não produz nada. [...]. Sem dúvida, que o trabalho, em suas formas históricas: escravidão, servidão, assalariado, aparece sempre como um trabalho repulsivo, como um trabalho forçado, imposto pelo exterior, frente ao qual o não-trabalho representa a liberdade e a felicidade. (MARX, 1985, p. 101).
}

Assim, mesmo na sociedade capitalista onde as relações de trabalho são constituídas por trabalhadores "livres", sem a presença da escravidão, o trabalho não é sinônimo de entretenimento ou puro prazer. Pois, as relações sociais na sociedade moderna estão sustentadas pelo valor de troca. Então, "no mundo moderno, as relações pessoais surgem como uma simples emanação das relações de produção e de troca" e não mais - como nas formas anteriores de propriedade - as relações de produção como derivadas das relações pessoais" (VIEIRA, 2004, p. 50). 


\section{Trabalhonecessário}

ISSN: 1808 - 799X

ANO 12, № 19 - 2014

\section{TRABALHO LIVRE E CRIATIVO COMO CONDIÇÃO HUMANA}

Qual o espaço de materialização da ética contemporânea? O espaço da materialização da ética contemporânea é na sociabilidade mediada pelo valor de troca.

O modo de produção também determina a sociabilidade, o tipo de relação tida com o resultado da própria produção e com a do outro. No pensamento marxiano, na sociedade capitalista, a divisão social do trabalho determina uma sociabilidade que contradiz o interesse do indivíduo singular ou da família singular e o interesse coletivo de todos os indivíduos que se relacionam entre si. Desta forma, o interesse coletivo existe apenas, enquanto interesse universal, como dependência recíproca dos indivíduos entre os quais é partilhado o trabalho. A divisão - a social e a técnica - existente numa sociedade sustentada em relações de troca aprisiona cada indivíduo numa esfera de atividade exclusiva e, dificilmente, conseguirá sair de um tipo de atividade ou profissão sem ameaçar a sua subsistência. Este trabalho, aprisionador e alienante, não pode fazer parte da condição humana, não se constituindo como necessidade humana.

E qual o campo da materialização da ética emancipatória? O espaço da materialização da ética emancipatória é na sociabilidade mediada pelo valor de uso, em que o trabalho é realizado como condição humana e não como condição do capital.

Karl Marx, em seu livro A Ideologia Alemã (p. 14), diz que, na sociedade comunista, na qual a produção geral será autorregulada, cada indivíduo poderá aperfeiçoar-se no campo que the aprouver, não tendo, por isso, uma esfera de atividade exclusiva. Esta flexibilidade da atividade social liberta nosso próprio trabalho, ou seja, o trabalho aparecerá como necessidade humana e como atividade livre. Livre para poder ser inventado, criado, reconhecendo que a 


\section{Trabalhonecessário}

ISSN: 1808 - 799X

ANO 12, № 19 - 2014

pessoa não possui apenas uma habilidade, mas sim que suas diversas habilidades são tolhidas nas relações mercadológicas.

No entanto, há de se prestar atenção em dois elementos da sua afirmação: a sociedade que regula a produção geral: se for a sociedade (seja através do Estado ou não) que regula a produção geral, não será o indivíduo particular que decidirá se quer produzir e o que vai produzir; então, será responsabilidade de todos e de todas a produção de bens fundamentais para a existência humana, ou seja, é a substituição da produção de riquezas por uma rica produção com controle social na produção e na distribuição. Em uma sociedade humana, sem a exploração de uma pessoa sobre a outra, será possível a produção sem a presença do valor de troca. Com isso, não se fará necessário o lucro, acúmulo de capital, mas sim uma produção efetivamente social, com distribuição social; portanto, com uma produção orientada pelo consumo (valor de uso) e não pela ganância de capital (valor de troca). Nesse tipo de relação, será possível o trabalho como possibilidade de criação e de realização humana. Assim, ter-se-ia a liberdade como real possibilidade de satisfação de necessidades, com o fim da presença do indivíduo centrado nos seus interesses particulares.

No entanto, entende-se que a libertação da divisão do trabalho escravizante será possível também com o fim da separação entre os que pensam - criam e possuem acesso a conhecimento possibilitador de autonomia - e aqueles que apenas executam decisões tomadas por essa cúpula pensante. Assim, ter-se-ia a possibilidade de todos satisfazerem outra necessidade humana básica: a da autonomia como possibilidade de criação e decisão - numa sociedade em que o trabalho estaria ao alcance de todas as pessoas e o estímulo para desenvolvê-lo seria o valor de uso.

O trabalho realizado na sociedade capitalista, apesar de se constituir como o único laço dos indivíduos às forças produtivas e à sua própria existência, não mais aparece, para os indivíduos, como manifestação de si e só lhes conserva a 


\section{Trabalhonecessário}

ISSN: 1808 - 799X

ANO 12, № 19 - 2014

vida definhando-a pela impossibilidade de autorrealização, por todo seu conteúdo alienante.

Sem o trabalho, é inviável qualquer produção de bens e, através dele, conquista-se a autonomia com a produção dos instrumentos necessários à transformação da natureza. Para Marx, o trabalho é a essência humana; no entanto, aquele possibilitador de criação e, consequentemente, possibilitador de objetivação, pois, através de sua criação, a pessoa o verá como fonte de realização humana. Contudo, o trabalho livre é possível com a livre associação de produtores, com a presença da cooperação voluntária e da autonomia na organização e gestão do trabalho.

Na sociedade capitalista, temos a produção de mercadorias. Segundo Marx (2005, p. 109a), "As mercadorias são coisas, portanto, inermes diante do homem [...]". Mas a mercadoria é uma coisa capaz de satisfazer necessidades humanas, independentemente da classe a que pertençam. A satisfação da necessidade constitui a condição sine qua non para qualquer mercadoria. Qualquer valor só existe pela utilidade do objeto (que satisfaz necessidades). Por outro, o valor de troca só se materializa por meio de uma relação entre pessoas por meio de um processo social. Resumidamente: um objeto só se torna mercadoria quando nele está contido o valor de troca. E, conforme destaque de Mészáros (2002, p. 606), o traço marcante do sistema capitalista desde seu início é a completa subordinação das necessidades humanas à reprodução de valor de troca no interesse da autorrealização ampliada do capital. Deste modo, a mercadoria é um objeto útil, produzido pelo trabalho humano, mas não destinado ao consumo do produtor e nem à troca de excedentes entre produtores; é colocado à venda no mercado e seu valor é determinado pelo tempo de trabalho despendido na sua produção, mediado pelo tempo de capacitação da força de trabalho, dos bens necessários à reprodução da capacidade de trabalho e organização política dos trabalhadores ou de dada categoria de trabalhadores. 


\section{Trabalhonecessário}

ISSN: 1808 - 799X

ANO 12, № 19 - 2014

A mercadoria é valor de uso ou objeto útil e "valor". Ela revela seu duplo caráter, o que ela é realmente, quando, como valor, dispõe de uma forma de manifestação própria, diferente da forma natural dela, a forma de valor de troca; e ela nunca possui essa forma, isoladamente considerada, mas apenas na relação de valor ou de troca com uma segunda mercadoria diferente (MARX, 2005, p. 82a).

Então, nas palavras de Marx (2005, p. 83a), "[...] o trabalho despendido na produção de uma coisa útil é propriedade objetiva, inerente a essa coisa, isto é, com o seu valor é que transforma o produto do trabalho em mercadoria". Portanto, "[...] não é a troca que regula a magnitude do valor da mercadoria, mas, ao contrário, é a magnitude do valor da mercadoria que regula as relações de troca" (2005, p. 85a).

Já na época de Marx certos escritores especializados pretendiam provar a eterna necessidade natural do capital. No debate com tais autores, ele dizia que, se o capital fosse representado na forma de materiais e dos meios de trabalho, ou os elementos objetivos do processo de trabalho, por certo, ele seria necessário em qualquer tipo societário, mas nunca o capitalista. Todavia, se assim fosse, capital seria apenas um nome dado a tudo o que é necessário para colocar em movimento um processo de trabalho. Mas Marx (2004, p. 67-68c) prossegue na sua análise crítica dizendo que capital não é um nome para identificar os elementos de um processo de produção. É "capital" porque a produção capitalista separou o produtor do resultado de seu próprio trabalho, é uma relação social baseada no valor de troca. E o objetivo do capitalista não é a produção em si, o que Ihes importa é o quantum de trabalho não pago que podem acumular, ou seja, a quantidade de mais-valor da quantia paga ao trabalhador pelo seu trabalho no processo de transformação de uma matéria-prima em um objeto utilizável.

Entre os autores criticados por suas concepções, ele dá destaque para Proudhon e F. Wayland. Conforme os escritos de Marx (p. 2005c), Wayland e 


\section{Trabalhonecessário}

ISSN: 1808 - 799X

ANO 12, № 19 - 2014

Proudhon distinguem "capital" e "produto" dentro do processo de produção e da circulação capitalista. Para o primeiro, o capital, seria a matéria-prima que, uma vez transformada, terá a forma de produto. Já Proudhon diz que o que transforma um produto em capital é a ideia de valor. Na concepção de "produto" de Karl Marx, perpassa a ideia do produto como valor de uso e, portanto, elaborado sem a presença do trabalho como mercadoria. Então, os produtos são resultantes de relações livres da exploração do trabalho como fonte de acumulação de riqueza privada.

Veementemente, Marx diz que, na produção capitalista, não há um produto, há uma mercadoria, embora nela esteja contido um valor de uso no processo final da produção, e o valor atribuído a ela é a quantidade de mais-valia extraída do trabalho; portanto, valor não é uma ideia, ele é objetivamente atribuído pelo trabalho. Este mais-valor sobre o trabalho é capital. Então, o capital materializa-se sob diferentes formas: dinheiro, matéria-prima elaborada e em coisas necessárias para a reprodução da vida e para outros processos de produção, os quais se apresentam como mercadorias. Assim, o capital está presente nas mais diferentes esferas de nossas vidas. Mas só há uma forma de o capital se objetivar: na relação de exploração do trabalhador. Assim, o produto do capitalista é a mais-valia possível pela apropriação do trabalho de outrem em diferentes espaços da sociedade capitalista e presente nas unidades de produção de mercadorias.

Onde há a associação de produtores livres, os quais produzem orientados pelo valor de uso, não há capital e nem a sociabilidade sustentada pelo valor de troca.

Considerando os princípios do cooperativismo autogestor e solidário, podemos afirmar que há clara distinção em relação a uma unidade de produção classicamente capitalista, pelo simples fato de nela configurar o trabalho como produtor de capital, ou seja, com a presença do excedente por decorrência da 


\section{Trabalhonecessário}

ISSN: 1808 - 799X

ANO 12, № 19 - 2014

extração da mais-valia e do trabalho subordinado ao capital e na unidade de trabalho cooperativado, não há a subsunção² real ao capital e nem um excedente acumulado com extração de mais-valia e, caso ocorra o excedente pela exploração do trabalho alheio, se configurará de unidade de capital.

$\mathrm{Na}$ unidade de trabalho gerida pelo conjunto dos trabalhadores, ou na terminologia de Marx, "produtores associados", o grupo de pessoas que colocam em movimento o processo de produção são produtores livres da apropriação do excedente de trabalho por um proprietário dos meios de produção, pois os meios de produção pertencem ao conjunto dos próprios trabalhadores, portanto, sem a presença do excedente caracterizado como mais-valia, ou seja, parte do trabalho não pago. Portanto, ao produzir riqueza, o produtor também enriquece a sua condição humana, produzindo livremente valores de uso e equitativamente participa da repartição da rica produção.

Mas qual a ética que orientará a repartição da riqueza produzida? $\mathrm{Na}$ crítica elaborada por Karl Marx, "Programa de Gotha3", encontram-se alguns elementos na discussão dos critérios de repartição dos produtos do trabalho a cada produtor em particular. Evidentemente, ele não dá por resolvido o debate; muito pelo contrário, considera o tema polêmico e historicamente delimitável. Mesmo assim, é referência para a reflexão sobre as retiradas mensais de cada associado. Resumidamente, na repartição entre produtores considerados individualmente, o princípio é este: uma mesma quantidade de trabalho, sob uma

\footnotetext{
${ }^{2}$ Karl Marx denomina subsunção do trabalho no capital a conversão do processo de trabalho em instrumento do processo de valorização ou do processo da autovalorização do capital: da criação de mais-valia - e o capitalista é dirigente deste processo, guiando o processo de exploração do trabalho alheio. Portanto, "o que, desde o início, distingue o processo de trabalho subsumido [...] é a escala em que se efetua; o mesmo é dizer, por um lado, a vastidão dos meios de produção adiantados e, por outro, a quantidade de operários dirigidos pelo mesmo patrão" (2004, p. 90c).
}

\footnotetext{
${ }^{3} \mathrm{O}$ texto é uma crítica ao projeto de programa do Partido Operário Unificado Alemão.
} 


\section{Trabalhonecessário}

ISSN: 1808 - 799X

ANO 12, № 19 - 2014

forma, troca-se por uma mesma quantidade de trabalho por produtos necessários à satisfação de necessidades humanas; a troca não necessariamente se dá por produtos, podendo ser através de vale (na nossa sociedade, dinheiro) para aquisição nas cooperativas de consumo. Ou seja,

[...] o direito igual continua aqui, portanto, no seu princípio, a ser o direito burguês, se bem que princípio e prática já não entrem em conflito, ao passo que hoje, para as mercadorias, a troca de equivalentes só existe em média e não nos casos individuais. (MARX, 2007, p. 13).

Segundo Marx, numa fase transitória, dificilmente serão superados os defeitos do direito burguês. Pois "o direito nunca pode ser mais elevado que o estado econômico da sociedade e o grau de civilização que lhe corresponde". Só quando o direito burguês estiver superado ou ultrapassado, a sociedade poderá adotar o critério de participação e distribuição da riqueza de acordo com as capacidades e necessidades das pessoas, ou seja, "De cada um segundo as suas capacidades, a cada um segundo as suas necessidades!" (MARX, 2007, p. 13).

Com a copropriedade, dos próprios trabalhadores, dos meios de produção, também a repartição dos objetos de consumo será coletivizada. Portanto, o modo da repartição individual não é independente do modo de produção (MARX, 2007, p. 13) e do tipo de propriedade dos meios de produção.

Pensando nas cooperativas de trabalho, organizadas por produtores livres da mais-valia, o excedente poderá existir depois de retirado todo o custo de manutenção da unidade de trabalho: dos recursos de produção e administração à manutenção da capacidade de trabalho; e, ainda, levando em consideração os 


\section{Trabalhonecessário}

ISSN: 1808 - 799X

ANO 12, № 19 - 2014

princípios do cooperativismo, a criação de fundos de educação e assistência aos cooperados e colaboração financeira para a criação de outras cooperativas.

A partir dessas considerações de Karl Marx, pode ser dito que numa sociedade emancipada da exploração do trabalho, onde reina a ética da solidariedade, da autonomia como marca da superação da alienação, a justiça entendida como garantia de uma rica produção e uma rica distribuição, teremos uma sociedade que se caracteriza pela troca solidária, em que o montante total a ser distribuído mensalmente a cada associado equivale às cotas-partes indispensáveis para a manutenção das necessidades humanas de cada produtor e de seus dependentes; fim da hierarquia na divisão do trabalho; equivalência entre responsabilidade e direito em que será dedicada cota-parte de trabalho para a produção de uma rica produção e cota-parte para manutenção da vida do ser singular; e igualdade desigual (fim do direito burguês) por se considerar as necessidades diferenciadas entre associados oriundas de eventos na vida privada do produtor associado.

\subsection{Limites e possibilidades da prática cooperativada na construção de uma racionalidade ética emancipadora}

O potencial das cooperativas de produção para dar novo significado ao trabalho com a superação do trabalho alienado pela relação capitalista já era reconhecido por Marx e Engels no capítulo primeiro de A ldeologia Alemã, no qual criticam as posições de Feuerbach quanto às concepções materialista e idealista da história. Tanto Marx quanto Engels tinham a clareza teórica e política de que a emancipação se realizava na práxis humana, donde a prática é sustentada com o conhecimento do real, mas não é ele, o conhecimento sem a prática política, que resultará numa possível libertação humana da exploração de um pelo outro. Marx e Engels são claros ao mencionar que não é possível conseguir a emancipação fora do mundo real e sem meios reais. E de modo algum é possível homens e 


\title{
Trabalhonecessário
}

ISSN: 1808 - 799X

ANO 12, № 19 - 2014

mulheres se libertarem se não estiverem em condições de atender as necessidades mais prementes do ser humano na qualidade e na quantidade exigidas para a manutenção da vida saudável.

\begin{abstract}
Não nos vamos, naturalmente, dar ao trabalho de esclarecer os nossos sábios filósofos sobre o fato de que a "libertação" do "Homem" não avançou um único passo por terem resolvido a filosofia, a teologia, a substância e todo o lixo na "Consciência de Si", por terem libertado o "Homem" do domínio destas frases sob as quais ele nunca foi escravo; de que não é possível conseguir uma libertação real a não ser no mundo real e com meios reais, de que não se pode abolir [aufheben] a escravatura sem a máquina a vapor e a mule-jenny, nem a servidão sem uma agricultura aperfeiçoada, de que, de modo nenhum, se pode libertar os homens enquanto estes não estiverem em condições de adquirir comida e bebida, habitação e vestuário na qualidade $\mathrm{e}$ na quantidade perfeitas. A "libertação" é um ato histórico, não um ato de pensamento, e é efetuada por relações históricas, pelo nível da indústria, do com[ércio], da [agri]cultura, do [inter]câmbio, então, ulteriormente, consoante as suas diferentes etapas de desenvolvimento, o absurdo da substância, do sujeito, da consciência de si e da critica pura, tal como o absurdo religioso e teológico, e depois o eliminam de novo quando estão suficientemente desenvolvidas [...] (MARX; ENGELS, 2006, p. 11).
\end{abstract}

No sentido de evidenciar o reconhecimento de Karl Marx do potencial da prática cooperativada como alternativa econômica e política de supressão das relações de assalariado e apropriação do excedente pelo capitalista, a anarquia da divisão social do trabalho e o despotismo da divisão hierárquica do trabalho, destacam-se algumas passagens de textos políticos de Karl Marx. É evidente que ele não desenvolveu nenhuma teoria sobre o comunismo e muito menos sobre o cooperativismo; ele se ateve a analisar o real, e o real é o sistema capitalista; contudo, defensor da práxis, Marx era um intelectual engajado na luta política dos trabalhadores para a superação da 


\section{Trabalhonecessário}

ISSN: 1808 - 799X

ANO 12, № 19 - 2014

sociedade capitalista e é em escritos decorrentes dessa prática política que ele destaca o movimento cooperativista da época.

A prática cooperativista aparece nas reflexões de Marx e Engels sobre o socialismo utópico no "Manifesto Comunista" e no manifesto de lançamento da Associação Internacional dos Trabalhadores em 1864. A crítica de Karl Marx e Friedrich aos socialistas utópicos aponta para a ausência da categoria "totalidade", por consequência da abdicação de ações políticas de toda a classe de trabalhadores, pois, segundo Marx, a ação de Saint-Simon, Fourier e Owen estava limitada às experiências fechadas e isoladas de autogestão, as quais são identificadas, no "Manifesto Comunista", como socialistas críticas-utópicas. Apesar de Karl Marx dizer que as propostas cooperativistas tinham um sentido puramente utópico, ele não deixou de ressaltar a importância prática dessas iniciativas por liberarem certo potencial crítico ao mostrar, com ações práticas concretas, que a abolição das relações de assalariamento é possível.

Mas essas obras socialistas e comunistas encerram também
elementos críticos. Atacam a sociedade existente em suas bases.
Por conseguinte, forneceram, em seu tempo, materiais de grande
valor para esclarecer os operários. Suas propostas positivas
relativas à sociedade futura, tais como a supressão da distinção
entre a cidade e o campo, a abolição da família, do lucro privado e
do trabalho assalariado, a proclamação da harmonia social e a
transformação do Estado numa simples administração da
produção. Todas essas propostas apenas anunciam o
desaparecimento do antagonismo entre as classes, antagonismo
que mal começa e que esses autores somente conhecem em
suas formas imprecisas. (MARX; ENGELS, 1997, p. 45-46).

Na fundação da Associação Internacional dos Trabalhadores, em 28 de setembro de 1864, realizada em St. Martin's Hall, Long Acre, Londres, Karl Marx fez o manifesto de lançamento da associação. Nele, o autor destaca a conquista da lei da jornada de trabalho de 10 horas e manifesta apreço pela experiência de Robert Owen (movimento cooperativo), considerando uma reservada vitória da economia política do trabalho sobre a economia política da 


\section{Trabalhonecessário}

ISSN: 1808 - 799X

ANO 12, № $19-2014$

propriedade, pois mostrava que, para a produção de riqueza, os meios de trabalho não precisam ser monopolizados como meios de domínio sobre o próprio trabalhador e de extorsão sobre o mesmo.

Deste modo, a Lei das Dez Horas não foi apenas um grande sucesso prático; foi a vitória de um princípio; foi a primeira vez que, em plena luz do dia, a economia política da classe média sucumbiu à economia política da classe operária. Mas, estava reservada uma vitória ainda maior da economia política do trabalho sobre a economia política da propriedade. Falamos do movimento cooperativo, especialmente, das fábricas cooperativas erguidas pelos esforços, sem apoio, de algumas "mãos" ousadas. O valor destas grandes experiências sociais não pode ser exagerado. Mostraram com fatos, em vez de argumentos, que a produção em larga escala e de acordo com os requisitos da ciência moderna pode ser prosseguida sem a existência de uma classe de patrões empregando uma classe de braços; que, para dar fruto, os meios de trabalho não precisam ser monopolizados como meios de domínio sobre e de extorsão contra o próprio trabalhador; e que, tal como o trabalho escravo, tal como o trabalho servo, o trabalho assalariado não é senão uma forma transitória e inferior, destinada a desaparecer ante o trabalho associado desempenhando a sua tarefa com uma mão voluntariosa, um espírito pronto e um coração alegre. $\mathrm{Na}$ Inglaterra, os germens do sistema cooperativo foram semeados por Robert Owen; as experiências dos operários, tentadas no Continente, foram, de fato, o resultado prático das teorias, não inventadas, mas proclamadas em alta voz, em 1848. (MARX, 2007, p. 7-8).

Apesar disso, ele continua a chamar a atenção para o fato de que as práticas libertadoras do trabalho assalariado nas cooperativas não libertam toda a classe. Para isso, é imprescindível a solidariedade com toda a classe de trabalhadores sem se manter restrito ao círculo das cooperativas já organizadas pelos trabalhadores e, se assim for, nunca serão capazes de cessar as relações capitalistas de trabalho e de libertar as massas de trabalhadores da expropriação do excedente pelo capital. Todavia, demonstrando respeito político pela iniciativa do movimento cooperativo, ele propõe que o trabalho cooperativo seja desenvolvido em dimensões nacionais e, evidentemente, internacionais. 


\section{Trabalhonecessário}

ISSN: 1808 - 799X

ANO 12, № 19 - 2014

Ao mesmo tempo, a experiência do período de 1848 a 1864 provou, fora de qualquer dúvida, que o trabalho cooperativo - por mais excelente que, em princípio, [seja] e por mais útil que, na prática, [seja] —, se mantido no círculo estreito dos esforços casuais de operários privados, nunca será capaz de parar o crescimento em progressão geométrica do monopólio, de libertar as massas, nem sequer de aliviar perceptivelmente a carga das suas misérias. É talvez por esta precisa razão que nobres bemfalantes, filantrópicos declamadores da classe média e mesmo agudos economistas políticos, imediatamente se voltaram todos com cumprimentos nauseabundos para o preciso sistema de trabalho cooperativo que em vão tinham tentado matar à nascença, ridicularizando-o como Utopia do sonhador ou estigmatizando-o como sacrilégio do Socialista. Para salvar as massas industriosas, o trabalho cooperativo deveria ser desenvolvido a dimensões nacionais e, consequentemente, ser alimentado por meios nacionais. Contudo, os senhores da terra e os senhores do capital sempre usarão os seus privilégios políticos para defesa e perpetuação dos seus monopólios econômicos. Muito longe de promover, continuarão a colocar todo o impedimento possível no caminho da emancipação do trabalho. (MARX, 2007, p. 8).

Porém, apesar de a proposta cooperativista de superação do trabalho alienado já existir desde os anos de 1800, ainda é presente o problema teórico e prático de se saber se este modo de produção autogestor e solidário é capaz de eliminar o despotismo da divisão hierárquica do trabalho e a anarquia da divisão social do trabalho, instituindo a cooperação voluntária e a coordenação participativa na organização e gestão do trabalho.

\subsubsection{Limites da superação da produção da riqueza pelo sistema cooperativo no interior do sistema capitalista na concepção de István Mészáros}

István Mészáros (2002), no capítulo "A produção de riqueza e a riqueza da produção", a partir dos escritos de Marx (Capital e Grundrisse), compara as determinantes da produção na antiguidade e no capitalismo, com o objetivo de evidenciar a diferença da mediação do valor de uso e valor de troca na produção da riqueza e na sua apropriação. 


\section{Trabalhonecessário}

ISSN: 1808 - 799X

ANO 12, № 19 - 2014

$\mathrm{Na}$ sociedade primitiva, a riqueza, como acúmulo privado, não aparece como finalidade da produção. A finalidade da produção era o ser humano: então, nas palavras de Marx e utilizadas por Mészáros (2002, p. 606), a "produção aparece como o objetivo da humanidade e a riqueza como o objetivo da produção". Ou seja, o fim era atender às necessidades humanas, donde a riqueza passa a ser analisada pela capacidade do sistema em dar resposta às carências de todos os integrantes de uma dada sociedade. E, para inverter a finalidade da produção - não mais a riqueza da produção e sim a produção de riqueza -, a produção capitalista separou o valor de uso do valor de troca, sob a supremacia do valor e não da utilidade. Exemplos, apresentados por Marx (2005, p. 357a), de comunidades em que a produção é voltada para o consumo e não para a produção de mercadorias e, consequentemente, de riqueza para capitalistas são as pequenas comunidades indianas que se baseiam na posse comum das terras, na união direta entre agricultura e artesanato e numa divisão fixa do trabalho. Outro exemplo, dado por Marx (2005, p. 282a) e mencionado por Mészáros (2002, p. 607), refere-se às "[...] determinações internas da produção e distribuição na estrutura do sistema de guildas e em relação ao sistema e às demandas do capital mercantil [...]". As guildas se defendiam das tendências do capital mercantil por meio da manutenção da produção de valores de uso. As leis das corporações limitam o número de ajudantes que um único mestre de corporação podia empregar, e tais ajudantes tinham o mesmo ofício do mestre da corporação. Assim, a corporação defendia-se de qualquer intrusão do capital mercantil. Ao comerciante, era permitida a compra de todas as mercadorias, mas não o trabalho como mercadoria. O comerciante apenas distribuía os produtos artesanais. E, se o desenvolvimento da corporação provocasse uma progressiva divisão do trabalho, as guildas "[...] dividiam-se em pequenas espécies ou fundavam novas corporações ao lado das antigas, porém, sem que diferentes ofícios se reunissem em uma oficina [...], excluindo, [...], portanto, a divisão 


\section{Trabalhonecessário}

ISSN: 1808 - 799X

ANO 12, № 19 - 2014

manufatureira do trabalho" (2005 p. 282a). É pouco provável que tal tipo de organização possa ser recriada em um estágio muito avançado do desenvolvimento social, pois "[...] todo o sistema de necessidades humanas, junto com as condições de satisfação, é radicalmente alterado no curso das transformações históricas" (MÉSZÁROS, 2002, p. 608).

Mas, conforme Mészáros (2002), a crítica socialista não pode se limitar a restaurar o valor de uso à sua importância passada: tem, sim, de promover a função adequada, dinâmica e criativa, de regulação do sociometabolismo, ou seja, dos mecanismos necessários ao organismo para a formação, desenvolvimento e renovação das estruturas sociais, e para a produção da riqueza necessária às manifestações interiores e exteriores da vida, bem como às reações sociais. Assim, conforme menciona Mészáros (2002, p. 610), para Marx, o valor de uso, em uma sociedade socialista futura, é inseparável da questão do desenvolvimento em todos os aspectos das necessidades e capacidades produtivas do indivíduo social, e tal desenvolvimento só é possível numa sociedade não mais determinada pelo antagonismo de classe e de seus interesses. A questão que preocupa Mészáros é a prática de retransformação da finalidade da produção, voltada para as necessidades de toda a humanidade. Esta questão prática fatalmente envolverá "[...] uma redefinição radical de 'riqueza', no mesmo espírito em que o significado distorcido pelo sentido capitalista de 'propriedade' necessita de uma redefinição radical [...]" (2002, p. 612-613).

$\mathrm{Na}$ análise marxiana de superação do modo de produzir capitalista, a produção é reorientada, a finalidade passa a ser uma rica produção, ou seja, uma produção suficiente para atender às necessidades de todos os seres habitantes do universo humano, sendo, em consequência, produzidas coisas úteis sem a mediação do valor de troca. Mas, para a superação do valor de troca, é indispensável o fim da propriedade dos meios de produção e da relação de 


\section{Trabalhonecessário}

ISSN: 1808 - 799X

ANO 12, № 19 - 2014

subordinação entre proprietários e não proprietários. E, com a associação de produtores, ter-se-ão, enfim, produtos e não mercadorias no processo final de produção. No entanto, para uma produção livre do capital, não basta a extinção da divisão técnica e burocrática do trabalho, pois, só a extinção dela não liberta da estrutura capitalista que impõe a produção e circulação de mercadorias. A divisão social do trabalho continuará, mas não mais guiada pela concorrência e, sim, como associação de produtores e com uma sociedade organizada planejando e definindo as coisas úteis de necessidade humana. Portanto, "as perspectivas da emancipação humana são inseparáveis do avanço historicamente viável - da produtividade. Isto não é apenas uma questão de aumento quantitativo do volume de bens à disposição de uma sociedade particular, medida em uma base per capita” (MÉSZÁROS, 2002, p. 614).

É por isso que, na visão de Marx, a diligência humana deve ser orientada para a riqueza da produção (isto é, "a universalidade das necessidades, capacidades, prazeres, forças produtivas, etc. do indivíduo") e em uma cada vez mais rica - mas, claro, não em um sentido estritamente material de riqueza - auto reprodução dos indivíduos sociais como o fim-em-si-próprio conscientemente adotado. O capital é, de longe, o mais poderoso regulador espontâneo da produção conhecido pela humanidade até o presente e não pode ser substituído por um vácuo socioeconômico. A dominação do capital sobre a sociedade só pode ser superada por uma ordem reprodutiva materialmente sensata e humanamente gratificante que assuma todas as funções metabólicas vitais deste modo de controle sem suas contradições. (MÉSZÁROS, 2002, p. 613).

Segundo Mészáros (2002, p. 613), ou a produção é conscientemente controlada pelos produtores associados a serviço das necessidades, ou o capital os controla impondo a eles seus próprios imperativos estruturais como premissas da prática social das quais não podem escapar. Assim sendo, a "auto-realização por meio da riqueza da produção (e não pela produção da riqueza alienante e reificada) [...] pode oferecer uma alternativa viável à cega espontaneidade auto-reprodutiva do capital e suas consequências 


\section{Trabalhonecessário}

ISSN: 1808 - 799X

ANO 12, № 19 - 2014

destrutivas". Contudo, numa sociedade onde a finalidade é a riqueza da produção e negação da riqueza alienante e reificada (tratada como coisa), sem a separação do produtor do resultado de sua produção, em que a finalidade é a produção de coisas úteis, o tempo de produção continuará definindo o valor das coisas, mas não mais pela duração do tempo de trabalho aplicado e sim pelo tempo dedicado à produção de coisas mais ou menos úteis para a coletividade dos seres humanos. Então, numa sociedade sem a presença do antagonismo de classe, "[...] o uso não mais determinará pelo mínimo tempo de produção; mas o tempo de produção dedicado a um artigo será determinado pelo grau de sua utilidade" (MARX apud MÉSZÁROS, 2002, p. 619).

Ampliar a produção, conforme Mészáros (2002), com o mesmo capital variável aplicado, ou seja, aumentar a produtividade, é uma necessidade do capitalista à medida que pode assegurar-lhe vantagem competitiva com a diminuição do valor do valor de troca. Porém, em relação ao uso genuíno correspondente à necessidade humana, nada é alterado, do ponto de vista capitalista pouco importando se é "necessidade" ou "uso", o que lhe interessa é a realização de seu capital em uma escala ampliada. Sobre a necessidade ou o uso, o capitalista não tem nenhum controle, pois não tem qualquer garantia de encontrar, no domínio misterioso regido pela "mão invisível" do mercado, "[...] a demanda efetiva e a capacidade de consumo capitalisticamente legitimadas equivalentes por suas próprias mercadorias. Muito menos, tem ele qualquer meio de determinar o uso ao qual o produto social, na sua inteireza, deve ser destinado." (MÉSZÁROS, 2002, p. 620).

$\mathrm{Na}$ sociedade capitalista, o capital está em todos os lugares, tanto na produção quanto na circulação das mercadorias. Além de uma divisão social do trabalho anárquica - daí ser a produção regida pelas leis de mercado, as quais não são voltadas para a produção de interesse de uma coletividade (portanto, sem controle social), e sim para a produção possibilitadora de acúmulo de riqueza 


\section{Trabalhonecessário}

ISSN: 1808 - 799X

ANO 12, № 19 - 2014

individual -, as coisas produzidas neste sistema são mercadorias porque o seu produtor também transformou sua capacidade de trabalho em mercadoria ao vendê-la, por um tempo determinado, ao dono do capital. Assim, a alienação será característica típica da realidade objetiva, desde a menor até a maior unidade fabril, pois suas atividades produtivas estão sob a regência do capital e "[...] necessariamente constituídas em conformidade com os imperativos material e organizacional de estrutura de mercadoria que se aplicam não menos ao trabalho vivo do que aos meios e ao material de produção" (MÉSZÁROS, 2002, p. 621).

Com base na premissa de Mészáros (2002) de que o capital está em todos os lugares, então, mesmo que uma unidade fabril seja regida pelos trabalhadores por meio da associação de produtores, se inserida numa sociedade capitalista, não terá como se isentar da presença do capital, tem-se que este se fará presente na aquisição dos meios de produção (trabalho morto produzido com a presença de mais-valia) e os produtores certamente seguirão as leis de mercado para manter a unidade em atividade e em condições de competir. Entendendo que o capital também se faz presente na comercialização das mercadorias, então pode ser dito que, pelo fato de as cooperativas consumirem mercadorias produtivas (matéria-prima, meios e instrumentos de trabalho) para colocar em movimento o seu processo de trabalho e para a reprodução da força de trabalho, existe a presença de capital no interior das unidades de trabalho coletivo e autogestor.

Portanto, seguindo o pensamento de Mészáros (2002), a superação da alienação dos meios e do material do trabalho vivo seria apenas uma pequena perturbação do processo metabólico capitalista, ou seja, apenas inquietação em alguns elementos do conjunto dos mecanismos necessários ao desenvolvimento e à renovação da estrutura capitalista e na reprodução dos valores que expressam e reforçam as relações que conferem unidade ao capitalismo. Para que esta perturbação seja mais efetiva na transformação do modo de produção, 


\section{Trabalhonecessário}

ISSN: 1808 - 799X

ANO 12, № 19 - 2014

ela necessitará ser complementada pela junção radical e permanente de todas as funções vitais de controle, tanto do processo de trabalho como da distribuição do produto social do próprio trabalho. O aspecto mais importante da superação desse processo de homogeneização é a superação da divisão e fragmentação do trabalho que acompanha a estrutura da produção de mercadorias, a qual priva totalmente o trabalho vivo da supervisão e do controle do processo de trabalho da sociedade, junto com a sua dimensão distributiva.

Seguindo o pensamento do autor, o qual evidencia a importância do controle global do processo de trabalho pelos produtores associados, a transformação do trabalho objetivado em capital e a propriedade do capital dos meios do trabalho passariam a ser consideradas o aspecto secundário da dominação autoritária do capital sobre o trabalho. Pois, uma vez instituído o controle global da produção, a finalidade deixaria de ser a produção de riqueza e assim também seria destituído o capital. Mas a "expropriação dos expropriadores" é um pré-requisito para as mudanças necessárias na institucionalização do controle sobre a distribuição do produto social total. É evidente que a simples mudança de proprietários dos meios de produção não altera a lógica de produção capitalista, não é apenas o direito de propriedade que determina a estrutura de um modo de produção, é um dos elementos, mas não o único.

O que necessita ser radicalmente alterado é o modo pelo qual o microcosmo reificado da jornada de trabalho singular e utilizado é reproduzido, apesar de suas contradições internas, através do 'macrocosmo' homogeneizado e equilibrado do sistema como um todo (MÉSZÁROS, 2002, p. 629).

Embora Mészáros (2002, p. 629) fale que as relações capitalistas de propriedade representam direitos - pré-requisito material de garantias legais sancionadas, com uma articulação substantiva do complexo global de reprodução sociometabólica, o qual necessita de uma reestruturação radical, qualitativamente diferente e conscientemente controlado, erigida a partir das autodeterminações 


\section{Trabalhonecessário}

ISSN: 1808 - 799X

ANO 12, № 19 - 2014

autônomas nas unidades de produção qualitativamente diferentes - pensa-se ser possível considerar a contribuição, no mínimo de aprendizado político, das cooperativas constituídas e organizadas por trabalhadores. No entanto, usando a linguagem de Mészáros, nas cooperativas de trabalho cooperado, pelo menos no nível do microcosmo, há de ser superada a alienação no processo de trabalho e, no mínimo, tem-se que usufruir dos resultados do trabalho e atendimento das necessidades humanas para além da reprodução da capacidade de trabalho, com relações sustentadas pela ética emancipatória em repartição dos resultados que estão além do direito burguês.

Enfim, uma rica produção com uma repartição sustentada na ética da necessidade - "[...] de cada um segundo as suas capacidades, a cada um segundo as suas necessidades!" (MARX, 2007, p. 13). Em outras palavras, há rica produção quando ela é voltada para o atendimento de necessidades humanas histórica e temporalmente criadas e com a participação coletiva no processo decisório sobre o que produzir ou que necessidades serão consideradas prioritárias. É o leque de necessidades coletivas, passíveis de atendimento, que determina a riqueza da produção. É a distribuição desigual, ou seja, que considera as diferentes necessidades do âmbito humano, que materializa a ética emancipadora dos valores burgueses de justiça. Afinal, ao produzir riqueza, o produtor também enriquece a sua condição humana, pois enriquece a condição humana uma rica produção com uma pobre distribuição.

\section{REFERÊNCIAS}

LESSA, Sérgio. O processo de produção/reprodução social: trabalho e sociabilidade. In: CAPACITAÇÃO em Serviço Social e Política Social. Módulo 2 Programa de capacitação continuada para assistentes sociais. Brasília: CFESS/ABEPSS/CEAD/UNB, 1999. 


\section{Trabalhonecessário}

ISSN: 1808 - 799X

ANO 12, № 19 - 2014

MARX, Karl (A). O Capital: crítica da economia política. Livro I. Volume 1. Tradução de Reginaldo Sant'Anna. 2. ed. Rio de Janeiro: Civilização Brasileira, 2005.

(B). O Capital: crítica da economia política. Livro I, volume 2. O processo de produção do Capital. Tradução de Reginaldo Sant'Anna. 2. ed. Rio de Janeiro: Civilização Brasileira, 2005.

(C). Capital VI - inédito de 0 Capital. Tradução Klaus Von Puchen. 2. ed. São Paulo: Centauro, 2004. 1985.

A miséria da filosofia. Tradução José Paulo Netto. São Paulo: Global,

Crítica da filosofia do direito de Hegel. Trad. Rubens Enderle e Leonardo de Deus. São Paulo: Boitempo, 2005.

Boitempo, 2012.

Crítica do Programa de Gotha. Tradução Rubens Enderle. São Paulo:

Social": $\quad$ de um aríticas Marginais ao Artigo "O Rei da Prússia e a Reforma $<$ www.marxists.org/portugues/marx/1844/glosascriticas.htm>. Acesso em: 13 set. 2005.

Mensagem Inaugural da Associação Internacional dos Trabalhadores. In: OBRAS escolhidas em três tomos. Editorial "Avante!" Tradução José Barata-Moura. Transcrição e HTML Fernando A. S. Araújo. Nov. 2007. Disponível em: <http://www.marxists.org/portugues/marx/1845/ideologiaalema-oe/cap1.htm>. Acesso em: 20 nov. 2007.

Sobre a questão judaica. São Paulo: Moraes, 1978.

MARX, Karl; ENGELS, Friedrich. A Ideologia Alemã. Tradução de Luis Cláudio de Castro e Costa. São Paulo: Martins Fontes, 1989.

(1845-46). Feuerbach. Oposição das Concepções Materialista e Idealista (Capítulo Primeiro de A Ideologia Alemã). Editorial "Avante!" Tradução do Alemão por Álvaro Pina. Transcrição José Braz e Maria de Jesus Coutinho. Jan. 2006. Disponível em: <http://www.marxists.org/portugues/marx/1845/ideologia-alemaoe/cap1.htm>. Acesso em: 20 out. 2006.

(1845-46). Manifesto do Partido Comunista. In: OBRAS escolhidas em três tomos. Editorial "Avante!" Origem da presente transcrição "Manifesto do Partido Comunista", Editorial "Avante!", Lisboa, Portugal, 1997. Tradução de José Barata Moura. Disponível em: <http://www.marxists.org/portugues/marx/1845/ideologia-alema-oe/cap1.htm>. Acesso em: 20 out. 2006.

MÉSZÁROS, István. Para além do capital: rumo a uma teoria da transição. Tradução Paulo César Castanheira, Sérgio Lessa. Campinas: UNICAMP/Boitempo, 2002. 


\section{Trabalhonecessário}

ISSN: 1808 - 799X

ANO 12, № 19 - 2014

PEREIRA, Potyara A. P. Necessidades humanas subsídios à crítica dos mínimos sociais. 2. ed. São Paulo: Cortez, 2002.

VIEIRA, Zaira Rodrigues. Atividade sensível e emancipação humana nos Grundrisse DE Karl Marx. Dissertação (Pós-Graduação em Filosofia)-Faculdade de Filosofia e Ciências Humanas da UFMG, Belo Horizonte, Universidade Federal de Minas Gerais, 2004.

Recebido em: 30/04/2014

Aprovado em: 20/09/2014 